Journal of Qualitative Criminal Justice \& Criminology

\title{
Book Review | Mean Lives, Mean Laws: Oklahoma's Women Prisoners
}

Melisa M. Jaris ${ }^{1}$

${ }^{1}$ Kansas State University

Published on: Aug 15, 2020

License: Creative Commons Attribution 4.0 International License (CC-BY 4.0). 
S.F. Sharp. Mean Lives, Mean Laws: Oklahoma's Women Prisoners. Rutgers University Press, 2014; 190 pp.; ISBN: 9780813562759.

Using a feminist strain approach, Susan Sharp's Mean Lives, Mean Laws: Oklahoma's Women Prisoners, investigates the impact of incarceration on women in the Oklahoma prison system and their families. Oklahoma incarcerates women at a rate of 135 per 100,000, the highest in the nation. The book examines this high incarceration rate by investigating factors such as childhood abuse and neglect which may continue into adulthood and that contribute to women's imprisonment. Sharp makes it clear that once in prison there are few avenues for the women to obtain education and healthcare or to maintain relationships with family on the outside.

When discussing a major point in the book, the "mean laws" of Oklahoma, Sharp argues that drug laws disproportionately affect women because women often tend to have more serious drug problems and are disproportionately in the lower ranks of drug dealing enterprises which make them easier targets for law enforcement. These women are thus referred to as "doubly deviant" (p. 7) -they commit less serious crime but they tend to continue their criminal behavior. Their recidivism may be due in part to their addiction or the need to support their children. Contributing factors to recidivism in Oklahoma include long sentences, the scant instances of probation granted, the 85 percent rule, and a complicated parole process.

Among incarcerated women in Oklahoma, Sharp found multiple factors that lead to drug addiction and higher incarceration rates. First was a lack of basic education. Over a quarter of these inmates were released without ever having received education in prison. Second, Sharp noted that over half of the women had major psychiatric problems, mood disorders, psychotic disorders, and post-traumatic stress disorder. Third, most incarcerated women were generally not the first individuals in their families to be incarcerated.

To mitigate some of these issues, the prison system attempted to provide programming, but with little to no funding, the programs were often short lived. In addition, programs were found to be limited in many ways including admission capacity, the number of beds for substance abuse recovery, medical care, work opportunities, and educational opportunities. As a result of such programming deficiencies, the majority of women released were not well prepared, if at all, to succeed.

With these factors in mind, Sharp also studied the problems surrounding reentry, for these women faced difficulties with employment, housing, health, substance abuse, and their families. Many also dealt with homelessness, a lack of transportation, debt, and the crushing stigma of a felony conviction. All of these factors contribute to higher risks of recidivism. 
Few of the formerly incarcerated women led productive, law-abiding lives upon release. Those who were successful, according to Sharp, used temporary housing, maintained sobriety, and returned to more stable families and jobs. Luckily, most of these women did not have serious health problems because few were fortunate enough to have health coverage like Medicaid. The women who were successful upon release cited a positive attitude as a significant contributing factor as well.

Sharp's study also spotlighted the fact that the outlook for children with incarcerated mothers was grim. These children were more likely to live in poverty and had unstable living arrangements, as well as multiple caregivers; they were more often placed in foster care. Maintaining mother-child contact during incarceration provides better outcome opportunities for both parties, but such arrangements were often difficult and expensive. Caregivers of these children were also burdened financially with the care of the child. As a result of these circumstances, the children were often depressed and had little opportunity to seek medical care and mental health treatment.

A key weakness of Sharp's book is that the analysis and arguments for changes to the system could be strengthened by conducting and comparing these findings to data on women serving time in other states. A key strength is the use of Tables throughout the book to graph data. Much of the data were listed in paragraph form throughout the text, and without the visual aid of tables, the information and statistics would have been muddled. Another strength was that chapters 5 (written by Juanita Ortiz) and 6 (written by Susan Sharp) make such a convincing argument about the reasons women recidivate. They point out that it should not be surprising that women recidivate. Rather, it is more surprising when they do not reoffend.

The book was effective at showing the reality for these women and their families. Mean Lives, Mean Laws was persuasive in showing the extent of the flaws in the prison system such as the lack of educational opportunities for the women. Strategies to attempt to fix the issues are offered; for example, allowing more women into the education program and getting more qualified instructors would strengthen the education program. Sharp's book also has important implications for policy with insights that could shape and craft corrections policies to more efficiently help women and their families with the issues described throughout. Overall, Mean Lives, Mean Laws is an easy yet informative read for students, academics, and laypersons alike. Sharp has accomplished an impressive piece of research that contributes to literature on mass incarceration and women in prison. 